\title{
Time-Varying Impact of Geopolitical Risks on Oil Prices
}

Juncal Cunado*, Rangan Gupta ${ }^{* *}$, Chi Keung Marco Lau ${ }^{* * *}$ and Xin Sheng ${ }^{* * * *}$

\begin{abstract}
This paper analyses the dynamic impact of geopolitical risks (GPRs) on real oil returns for the period February 1974 to August 2017, using a time-varying parameter structural vector autoregressive (TVP-SVAR) model. Besides the two variables of concern, the model also includes growth in world oil production, global economic activity (to capture oil-demand), and world stock returns. We show that GPRs (based on a tally of newspaper articles covering geopolitical tensions), in general, has a significant negative impact on oil returns, primarily due to the decline in oil demand captured by the global economic activity. Our results, thus, highlight the risk of associating all GPRs with oil supply shocks driven by geopolitical tensions in the Middle East, and hence, ending up suggesting that higher GPRs drive up oil prices.
\end{abstract}

Keywords: Oil markets; geopolitical risks; time-varying parameter structural vector autoregressive (TVP-SVAR) model.

JEL Classification: C32, Q43.

\footnotetext{
Corresponding author. University of Navarra, School of Economics, Edificio Amigos, E-31080 Pamplona, Spain. Email: jcunado@unav.es. Juncal Cunado gratefully acknowledges financial support from the Ministerio de Economia y Competitividad (ECO2017-83183R).

Department of Economics, University of Pretoria, Pretoria, 0002, South Africa. Email: rangan.gupta@up.ac.za.

Huddersfield Business School, University of Huddersfield, Huddersfield, HD1 3DH, United Kingdom. Email: c.lau@ hud.ac.uk.

**** Huddersfield Business School, University of Huddersfield, Huddersfield, HD1 3DH, United Kingdom. Email: x.sheng@hud.ac.uk.
} 


\section{Introduction}

Oil production and prices have played a relevant role in the global economy, and thus, have been a popular topic of research in decades, for several reasons. First, oil price shocks have been widely considered as one of the main factors explaining economic crisis. Hamilton (1983), for example, pointed out that ten out of eleven US recessions since World War II were preceded by a spike in oil prices. At the same time, the literature also shows that the relationship of oil prices and economic activity has changed over time, and appears to be weaker since 1985 (Hooker, 1996; Hamilton, 2003). Second, oil remains the world's leading fuel, accounting for one-third of global energy consumptions (BP Statistical Review of World Energy, 2017), making the oil market an objective of different energy and climate change policies. Third, oil prices, as those of other commodities, have experienced large increases and decreases, raising its volatility during the last decades (Silvennoinen and Thorp, 2013). Furthermore, the so-called "financialization" of the commodities market (Basak and Pavlova, 2016; Fattouh et al., 2013) has opened the debate on whether the commodity prices are still driven by supply and demand factors (Krugman, 2008; Hamilton, 2009; Kilian, 2009) or they are also driven by excessive speculation. Fourth, investments in oil could be used as a diversification and a hedging tool (Babalos et al., 2015), although its effectiveness as a hedging tool changed over the last decades. In fact, prior to 2000s, investments in oil, due to their null or negative correlation with stock returns, were used as a diversification and a hedging tool (Babalos et al., 2015), while after the global crisis oil prices became more correlated with each other and with stock prices (Tang and Xiong, 2012; Silvennoinen and Thorp, 2013). The literature has also considered the endogenous nature of oil variables and has analysed the main factors affecting oil prices and oil production (Barsky and Kilian, 2002, 2004), determining that the impact of oil price shocks on economic and financial variables are different depending on the nature of the oil price shocks (Kilian, 2009). Accordingly, oil supply shocks or disruptions 
of crude oil production are associated with exogenous political events or geopolitical risks, while global and specific demand shocks are linked to an increase in the demand for all industrial commodities or in the demand for crude oil due to a precautionary effect caused by uncertainty about oil supply shortfalls.

In this framework, there is no doubt on the interaction of oil market variables with geopolitical, macroeconomic and financial variables. While the interaction of oil market variables with macroeconomic and financial variables has widely been analysed (Barsky and Kilian, 2002, 2004; Hamilton, 2003; Kilian, 2009), the impact of geopolitical risks (or some proxy variables such as terrorism or conflicts) on oil variables has been hardly studied, with some exceptions, partly due to measurement difficulties (Blomberg et al,, 2009; Antonakakis et al., 2017a, b; Monge et al., 2016; Caldara and Iacoviello, 2018; Fattouh, 2011). Blomberg et al. (2009) show that terrorism cause larger impact on oil prices in periods in which the global capacity is tight. Antonakakis et al. (2017a) analyse the spillovers between oil and stock markets and find that these spillovers seem to peak during periods of economic turbulence and geopolitical unrest, such as the $2^{\text {nd }}$ war in Iraq and the start of the Arab Spring in 2010. Monge et al. (2016) use unit root and fractional integration techniques to analyse the persistence and time series properties of oil prices before and after different military conflicts and political events, and they do not observe significant differences in oil prices before and after the geopolitical conflicts. In order to measure this variable, Caldara and Iacoviello (2018) proposed to measure the Geopolitical Risks (GPRs) Index counting the occurrence of words related to geopolitical tensions in leading international newspapers. A graphical inspection of this variable showed that this GPR index spikes around the Gulf War, after 9/11, during the 2003 Iraq invasion, during the 2014 Russia-Ukraine crisis, and after the Paris terrorist attacks. Using this index in a constant-parameter structural VAR, Caladara and Iacoviello (2018), showed that oil prices are negatively affected by geopolitical risks, due to contraction in outputs of 
developed and emerging countries. Antonakakis et al. (2017b), including this index in a $\operatorname{VAR}(p)$-BEKK-GARCH $(1,1)$ model over a century of data, along with oil and stock returns, find that geopolitical risks trigger a negative effect on oil returns and volatility, and to a smaller degree reduces the covariance between the oil and stock markets with a time lag. ${ }^{1}$

In this context, the objective of this paper is to analyse, for the first-time, the dynamic properties of oil prices with the GPR index developed by Caladara and Iacoviello (2008), in a full-fledged time-varying parameter structural vector autoregressive (TVP-SVAR) model of the oil market as outlined by Kilian and Park (2009). GPRs are often cited by central bankers, financial press and business investors as one of the determinants of investment decisions, and hence, are believed to affect business cycles and financial markets (Caldara and Iacoviello, 2018). When more than 1,000 investors were surveyed by Gallup in 2017, 75 percent of respondents expressed concerns about the economic impact of the various military and diplomatic conflicts taking place around the world. In the process, geopolitical risk was ranked ahead of political and economic uncertainty. ${ }^{2}$ In addition, Carney (2016) included GPRs, along with economic and policy uncertainty, among an 'uncertainty trinity' that could have significant adverse economic effects. More recently, in the April 2017 Economic Bulletin of the European Central Bank, and in the October 2017 World Economic Outlook of the International Monetary Fund, geopolitical uncertainties are highlighted as a salient risk to the economic outlook. Now, given that GPRs affect the economic conditions of both developed and emerging markets (Caldara and Iacoviello, 2018), and oil prices are functions of the state of the economy, it is expected, intuitively, that oil market movements are likely to be affected by risks associated with geopolitical events. In addition, with GPRs also affecting financial markets as discussed in detail by Balcilar et al., (2018), and with oil and financial

\footnotetext{
${ }^{1}$ While analysing rare disaster risks, Demirer et al., (forthcoming), as a part of robustness check, showed that GPRs can predict oil returns and volatility in a nonparametric causality-in-quantiles framework.

${ }^{2}$ See http://www.businesswire.com/news/home/20170613005348/en/.
} 
markets connected closely, such risks can also affect the oil prices indirectly through asset markets.

The main contribution of this paper is that with the methodology we are pursuing, based on the work by Akram and Mumtaz (2017), we are able to analyse whether the trends, volatility and cross-correlation of oil returns with GPRs (as well as the other control variables related to the oil market, namely, global oil production, global economic activity capturing oil-demand, and global stock market performance via its returns) have changed over time, spanning the monthly period of over half a century (February 1974 to August 2017). Note that over this period oil market variables have shown a very heterogeneous behaviour, and our sample also covers major geopolitical turbulences economic recessions, such as the 2008 global financial crisis. The layout of the rest of the paper is as follows: Section 2 describes the methodology, while Section 3 presents the data used in the empirical analysis, and the main results. Finally, Section 4 concludes.

\section{Methodology}

Following Akram and Mumtaz (2017), we use a framework, based on Bayesian estimation of the following time-varying parameter VAR model:

$\left[\begin{array}{l}Y_{1, t} \\ Y_{2, t}\end{array}\right]=C_{t}+\left[\begin{array}{cc}B_{1, t}(L) & 0 \\ B_{2, t}(L) & B_{3, t}(L)\end{array}\right]\left[\begin{array}{l}Y_{1, t} \\ Y_{2, t}\end{array}\right]+\varepsilon_{t}$

where $Y_{1, t}$ represents the variable measuring GPRs (considered to be exogenous (Caldara and Iacoviello, 2018)); and $Y_{2, t}$ is a data matrix, which includes growth in oil production and global economic activity, and oil and stock returns; $B_{i, t}(L)$ is a lag polynomial with $L$ lags (which we set to 2, based on the Bayesian Information Criterion (BIC)), and; $C_{t}$ is a vector of time varying intercepts. The variance (covariance) matrix of the innovations $\varepsilon_{t}$ is defined as:

$\operatorname{Var}\left(\varepsilon_{t}\right)=\Omega_{t}=A_{t}^{-1} \Sigma_{t} \Sigma_{t}^{\prime}\left(A_{t}^{-1}\right)^{\prime}$ 
where $A_{t}$ is the lower triangular matrix with ones on the diagonal:

$$
\left[\begin{array}{ccc}
1 & \cdots & 0 \\
\vdots & \ddots & \vdots \\
a_{i 1, t} & \cdots & 1
\end{array}\right]
$$

with $\Sigma_{t}$ is the diagonal matrix:

$$
\left[\begin{array}{ccc}
h_{1, t} & \cdots & 0 \\
\vdots & \ddots & \vdots \\
0 & \cdots & h_{i, t}
\end{array}\right]
$$

and $h_{i, t}$ follows a geometric random walk process:

$\operatorname{Ln}\left(h_{i, t}\right)=\operatorname{Ln}\left(h_{i, t-1}\right)+\eta_{t}$

Let $a_{t}$ be the vector of elements in the lower triangular matrix (stacked by rows) and $B_{t}$ be the vector stacked all the right-hand-side coefficients in (1). Both $a_{t}$ and $B_{t}$ can be specified by the simple random walk model without drift as follows:

$a_{t}=a_{t-1}+\xi_{t}$

$B_{t}=B_{t-1}+v_{t}$

It is assumed that all the innovations in the system are jointly normally distributed (i.e., $V=\left[\varepsilon_{t}^{\prime}, \eta_{t}^{\prime}, \xi_{t}^{\prime}, v_{t}^{\prime}\right], V \sim N(0, H)$, with the following assumptions on the variance (covariance) $H$ :

$$
H=\operatorname{Var}\left(\left[\begin{array}{c}
\varepsilon_{t} \\
\eta_{t} \\
\xi_{t} \\
v_{t}
\end{array}\right]\right)=\left[\begin{array}{cccc}
\Omega_{t} & 0 & 0 & 0 \\
0 & Q & 0 & 0 \\
0 & 0 & S & 0 \\
0 & 0 & 0 & G
\end{array}\right]
$$

where $\Omega_{t}$ is an identity matrix. $\mathrm{Q}, \mathrm{S}$, and $\mathrm{G}$ are positive definite matrices.

The time-varying parameter VAR model in (1) can be written in companion form as follows:

$Y_{t}=C_{t}+F_{t} Y_{t-1}+\varepsilon_{t}$ 
where $Y_{t}$ represents the five variables of concern in our model; $C_{t}$ is a vector of time-varying intercepts; $F_{t}$ is a matrix of time-varying parameters, and; $\varepsilon_{t}$ are heteroscedastic innovations.

The time-varying unconditional mean of each variable can be calculated as:

$E\left(Y_{t}\right)=e_{N}\left(I-F_{t}\right)^{-1} \mu_{t}$

where $e_{N}$ is a matrix that selects the first $\mathrm{N}$ elements of $E\left(Y_{t}\right)$.

The unconditional standard deviation of each variable is:

$s d\left(Y_{t}\right)=\left[e_{N}\left(I-F_{t} \otimes F_{t}\right)^{-1} \operatorname{vec}\left(\Omega_{t}\right)\right]^{1 / 2}$

The time-varying co-movement between variables $i$ and $j$ at time $t$ is measured by the dynamic correlation, which can be defined as follows:

$$
\frac{\hat{c}_{i, j}(w)}{\left[\hat{f}_{t}^{i i}(w) \hat{f}_{t}^{j j}(w)\right]^{1 / 2}}
$$

where $\hat{c}_{i, j}(w)$ represents the cospectrum between the variables at frequency $w ; \hat{f}_{t}^{i i}(w)$ and $\hat{f}_{t}^{i i}(w)$ are the model implied spectral density matrices of variables $i$ and $j$, and can be calculated as:

$\hat{f}_{t}(w)=\left(I-F_{t} e^{-i w}\right)^{-1} \frac{\Omega_{t}}{2 \pi}\left[\left(I-F_{t} e^{-i w}\right)^{-1}\right]^{\prime}$

The dynamic correlation has a range from -1 to 1 . It is equal to 1 when variables $i$ and $j$ are perfectly synchronised at the same frequency.

\section{Data and Results}

The data used in the TVP-SVAR model comprises of five variables: geopolitical risks, oil production, global economic activity, global oil and stock prices, with the variables ordered as mentioned, following Antonakakis et al., (2017a). Since the estimation requires the variables to be approximately stationary, we use the growth rate of oil production, and oil and stock log-returns, with the global activity variable already in growth rate in its raw-form. As far as the GPRs index is concerned, we use its natural logarithmic form, given that it is 
already mean-reverting by design. The data sample covers the monthly period of 1974:02 to 2017:08, with the start and end dates being purely driven by data availability of the variables used at the time of writing this paper. The data has been plotted in Figure A1, along with summary statistics provided in Table A1 in the Appendix.

Data for the oil price and world oil production have been extracted from the Energy Information Administration (EIA), whereas the data for the real global economic activity index have been retrieved from Professor Lutz Kilian's personal website. ${ }^{3}$ The measure of world oil price used in this paper is the U.S. crude oil imported acquisition cost by refiners quoted in U.S. dollars, based on the suggestions of Kilian (2009). The global stock market activity is captured by the Morgan Stanley Capital International (MSCI) world stock index in U.S. dollars. The nominal oil and stock prices are deflated by the U.S. consumer price index to convert them into their real terms. The CPI is derived from the FRED database of the Federal Reserve Bank of St. Louis, while the stock index is sourced from Datastream of Thomson Reuters.

Monthly data on geopolitical risks (GPRs) are based on the work of Caldara and Iacoviello (2018). ${ }^{4}$ Caldara and Iacoviello (2018) constructs the GPR index by counting the occurrence of words related to geopolitical tensions, derived from automated text-searches in 3 newspapers (The New York Times, the Chicago Tribune, and the Washington Post). ${ }^{5}$ Then, Caladara and Iacoviello (2018) calculate the index by counting, in each of the abovementioned 3 newspapers, the number of articles that contain the search terms above for every month starting in 1985 . The index is then normalized to average a value of 100 in the 20002009 decade.

\footnotetext{
${ }^{3}$ http://www-personal.umich.edu/ lkilian/paperlinks.html.

${ }^{4}$ The data can be freely downloaded from: https://www2.bc.edu/matteo-iacoviello/gpr.htm.

${ }^{5}$ As a robustness check, we also used another version of the GPRs index, which starts in 1985, based on leading 11 national and international newspapers (The Boston Globe, Chicago Tribune, The Daily Telegraph, Financial Times, The Globe and Mail, The Guardian, Los Angeles Times, The New York Times, The Times, The Wall Street Journal, and The Washington Post). Our results were qualitatively similar to those reported in the paper, but are available upon request from the authors.
} 
The search identifies articles containing references to six groups of words: Group 1 includes words associated with explicit mentions of geopolitical risk, as well as mentions of military-related tensions involving large regions of the world and a U.S. involvement. Group 2 includes words directly related to nuclear tensions. Groups 3 and 4 include mentions related to war threats and terrorist threats, respectively. Finally, Groups 5 and 6 aim at capturing press coverage of actual adverse geopolitical events (as opposed to just risks) which can be reasonably expected to lead to increases in geopolitical uncertainty, such as terrorist acts or the beginning of a war.

We now use the TVP-SVAR model to study possible changes in the time series properties of the five variables under consideration. We examine the dynamics of long-run unconditional mean, stochastic volatility, and long-term co-movements between GPRs and the various variables in the model, with focus on oil returns, over the period of 1978:06 to 2017:08. Note that, the estimation algorithm is initialised (and priors set) by using a presample of 50 observations, as in Akram amd Mumtaz (2017). This pre-sample and the two lags used in estimation imply that the effective sample starts in June 1978.

Figure 1 shows the model implied time-varying trends of variables, along with the $68 \%$ lower (LCB) and upper (UCB) confidence bands and the actual data. We find that the estimated time-varying unconditional means of oil production growth, real oil and stock returns are close to zero, and remain stable over time. The estimated means of global economic activity fluctuates across zero, and display a pattern of business cycles. We observe a notable fall in the unconditional mean of world economic activity after the global financial crisis of 2008. Moreover, there has been a gradual increase in the long-run mean of geopolitical risks since the global financial crisis.

(Insert Figure 1 around here) 
Figure 2 plots the stochastic volatility of the various shocks from the model. We find that the volatility of shocks to growth in world oil production declines over time. By contrast, the volatility of shocks to real oil returns has increased since 1985 and fluctuated dramatically. There is a large increase in the volatility of global economic activity in the last two decades, which coincides with relatively high volatility of real oil and stock returns and GPRs.

\section{(Insert Figure 2 around here)}

Figure 3(a) shows the estimated dynamic correlation between real oil returns and GPRs at the long-run frequency, which in turn, is negative and significant in general, especially at the early part of the sample. The relationship turned positive, though mostly insignificant in the wake of US's invasion of Iraq and the start of the war there, and also rising middle-east tensions following the assassination of Sheikh Ahmed Ismail Hassan Yassin - a founder of Hamas: an Islamist Palestinian paramilitary organization and political party. The correlation, though weakly negative thereafter is generally insignificant, which corresponds to the period of low oil prices because of weak demand in the wake of slowing down of global economic activity, following the global financial crisis and the "Great Recession". The negative impact of GPRs on the oil returns seems to be operating through two channels, as shown in Figure 3(b): (1) A direct one, whereby GPRs oil production and global economic activity, i.e., oil demand, with the latter going down more in the early part of the sample, and towards the end of the sample. Post 2000, even though GPRs increased, global economic activity increased as well due to a strong performances of the overall world economy in general, pushing the oil prices through the demand channel, though the relationship between real oil returns and GPRs was not statistically significant during this period; (2) An indirect channel possibly operates through the stock market. Heightened GPRs is shown to increase stock returns in general (as shown in Figure 3(b)) possibly via an addition of the risk-premium, and given that stock returns and oil returns have a well-known 
negative relationship (see Balcilar et al., (2015) for a detailed historical discussion in this regard spanning over 150 years of history of oil and stock markets), ${ }^{6}$ this tends to also make the oil returns and GPRs move in opposite directions. The increased oil demand and stock returns due to GPRs in the early 2000s, is causing the oil returns to move in opposite directions, causing the effect to be insignificant, with the oil demand effect dominating. As oil demand decreased post the global financial crisis, and in the wake of increased GPRs (resulting from events like announcement of the death of Osama Bin Laden, escalation of the Syrian and Russia-Ukraine crises, Turkish coup attempt, Paris terrorist attacks, middle-east concerns, and heightened tensions between North Korea and the US) oil returns decreased sharply. Even though the oil demand started to rise via increase in global economic activity post the "Great Recession", higher oil production kept the oil returns low during the last few years of our sample period characterized by high GPRs. ${ }^{7}$

\section{(Insert Figure 3 around here)}

\section{Conclusions}

The importance of the oil prices for the global macroeconomy is well-stablished. Hence, what drives the oil market is an important question for academics and policymakers alike. More recently, the role of geopolitical uncertainties has also been stressed as affecting the state of the economy. Given this, in this paper, we analyse the dynamic impact of geopolitical risks

\footnotetext{
${ }^{6}$ This was also observed in our dataset. Complete details of the time-varying oil and stock real returns correlation, along with all other correlations obtained from the model, are available upon request from the authors.

${ }^{7}$ Based on the search groups 1 to 6 discussed in the data segment, Caldara and Iacoviello (2018) further disentangle the direct effect of adverse geopolitical events from the effect of pure geopolitical risks by constructing two indexes: The Geopolitical Threats (GPTs) index, which only includes words belonging to Search groups 1 to 4, and; the Geopolitical Acts (GPAs) index, based on only words belonging to Search groups 5 and 6. In Figure A2 in the Appendix of the paper, we present a comparison of the standardized dynamic correlation between oil-returns with GPAs, GPRs, and GPTs. As can be seen, while the pattern of the correlation is similar, GPR has a much stronger impact than GPT and GPA on oil returns towards the end of the sample. Also, during early 2000s, starting with the 9/11 attacks, Iraq Invasion, middle-east tensions, a series of bombings like the ones in Madrid and London, and the Arab Spring, led the real oil returns to have a positive correlation with GPAs, which in turn also affected the correlation with overall GPRs. The short-lived positive relationship with GPTs, is possibly due to the threats associated with the South Ossetian War Escalation. So these results are in line with the conventionally held view that higher geopolitical risk drives up oil prices.
} 
on real oil returns for the period February 1974 to August 2017, using a time-varying parameter structural vector autoregressive (TVP-SVAR) model. Besides the two variables of concern, the model also includes growth in world oil production, global economic activity (to capture oil-demand), and world stock returns. We show that an index of geopolitical risks, based on a tally of newspaper articles covering geopolitical tensions, in general, has a significant negative impact on oil returns, driven primarily due to decline in oil demand captured by the global economic activity. Our result, thus nullifies the conventional belief that geopolitical risks drive up oil prices persistently - a view that might be a reflection of selective memory that associates all geopolitical risks with oil supply shocks driven by tensions in the Middle East. Hence, for the perspective of academics, besides macroeconomic and financial factors, we can add geopolitical uncertainty as a predictor of oil price movements. And from a policymaker's angle, especially for oil-exporting countries, the attempt should be to try and reduce geopolitical risks, to prevent oil price declines and hence, a fall in oil revenue, which in turn could drive their economies into deeper recessions. In general, attempts should be made to neutralize geopolitical risks, as they negatively impact the global economic activity, and the oil market through reduced demand. 


\section{References}

Akram, Q. F., and Mumtaz, H., 2017. Time-Varying Dynamics of the Norwegian Economy. The Scandinavian Journal of Economics. DOI: https://doi.org/10.1111/sjoe.12270.

Antonakakis, N., Chatziantoniou, I. and Filis, G., 2017a. Oil shocks and stock markets: Dynamic connectedness under the prism of recent geopolitical and economic unrest. International Review of Financial Analysis, 50(C), 1-26.

Antonakakis, N., Gupta, R., Kollias, C., Papadamou, S., 2017b. Geopolitical risks and the oilstock nexus over 1899-2016. Financial Research Letters 23, 165-173.

Babalos, V., Stravoyiannis, S., and Gupta, R., 2015. Do commodity investors herd? Evidence from a time-varying stochastic volatility model. Resources Policy 46, 281-287.

Balcilar, M., Bonato, M., Demirer, R., and Gupta, R., 2018. Geopolitical Risks and Stock Market Dynamics of the BRICS. Economic Systems, 42(2), 295-306.

Balcilar, M., Gupta, R., and Miller, S.M., 2015. Regime Switching Model of US Crude Oil and Stock Market Prices: 1859 to 2013. Energy Economics, 49, 317-327.

Barsky, R.B., and Kilian, L., 2002. Do we really know that oil caused the Great stagflation? A monetary alternative. NBER Macroeconomics Annual 2001, MIT Press, Cambridge, MA, 137-183.

Barsky, R.B., and Kilian, L., 2004. Oil and the macroeconomy since the 1970s. Journal of Economic Perspectives 18, 115-134.

Basak, S., Pavlova, A. 2016. A model of financialization of commodities. Journal of Finance 71, 1511-1556.

Blomberg, B., Hess, G., and Jackson, H., 2009. Terrorism and the returns to oil. Economics and Politics 21, 409-432. 
BP Statistics Review of World Energy, June 2017

(https://www.bp.com/content/dam/bp/en/corporate/pdf/energy-economics/statistical-review-

2017/bp-statistical-review-of-world-energy-2017-full-report.pdf)

Caldara, D. and Iacoviello, M., 2018. Measuring geopolitical risk. Working Paper, Board of Governors of the Federal Reserve Board.

Carney, M., 2016. Uncertainty, the economy and policy. Speech at the Bank of England, London, 30 June 2016. Accessed June 25, 2018 from: https://www.bis.org/review/r160704c.pdf.

Demirer, R., Gupta, R., Suleman, T., and Wohar, M.E., Forthcoming. Time-Varying Rare Disaster Risks, Oil Returns and Volatility. Energy Economics.

Fattouh, B., 2011. Oil market dynamics in turbulent times. Oxford Institute for Energy Studies.

Fattouh, B., Kilian, L., Mahadeva, L. 2013. The role of speculation in oil markets: what have we learned so far? The Energy Journal 34, 7-33.

Hamilton, J., 1983. Oil and the macroeconomy since World War II. Journal of Political Economy 91, 228-248.

Hamilton, J., 2003. What is an oil shock. Journal of Econometrics 113, 363-396.

Hamilton, J. 2009. Causes and consequences of the oil shock of 2007-08. Brookings Papers on Economic Activity 1, 215-261.

Hooker, M., 1996. What happened to the oil price-macroeconomy relationship? Journal of Monetary Economics 38, 195-213.

Kilian, L., 2009. Not all oil price shocks are alike: disentangling demand and supply shocks in the crude oil market. American Economic Review 99, 1053-1069.

Kilian, L., and Park, C., 2009. The impact of oil price shocks on the US stock market. International Economic Review, 50(4), 1267-1287. 
Krugman, P. 2008. More on oil and speculation. New York Times, May 13.

Monge, M., Gil-Alana, L.A., Perez de Gracia, F., 2016. Crude oil price behaviour before and after military conflicts and geopolitical events. Energy 120, 79-91.

Primiceri, G. E. (2005). Time varying structural vector autoregressions and monetary policy. The Review of Economic Studies, 72(3), 821-852.

Silvennoinen, A., and Thorp, S. 2013. Financialization, crisis and commodity correlation dynamics. Journal of International Financial Markets, Institutions and Money 24, 42-65.

Tang, K., Xiong, W. 2012. Index investment and the financialization of commodities. Financial Analysts Journal 68, 6. 
Figure 1. Time-Varying Unconditional Means of Variables
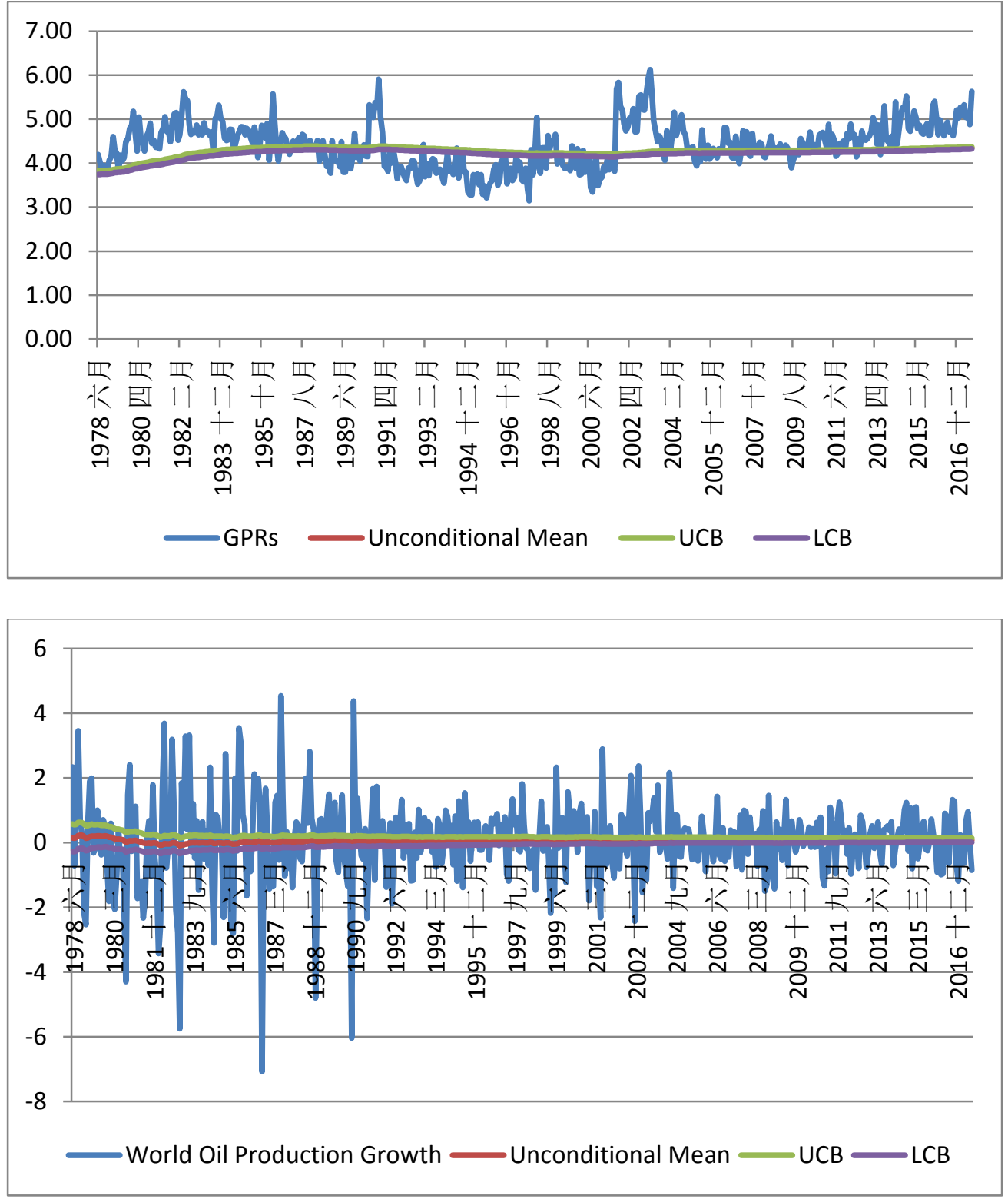

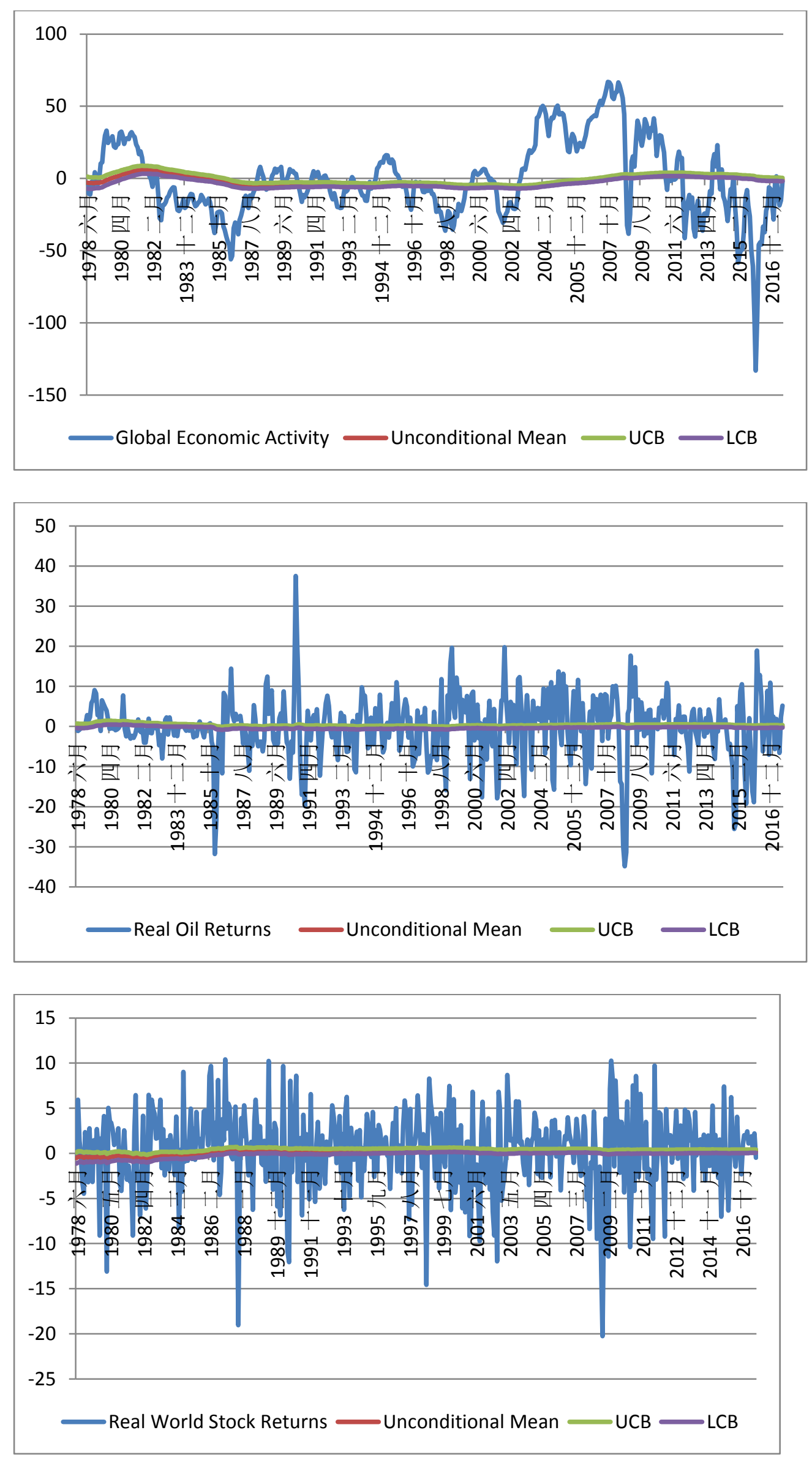

Note: LCB and UCB in Figures stand for lower and upper $68 \%$ confidence bands. 
Figure 2. Stochastic Volatility
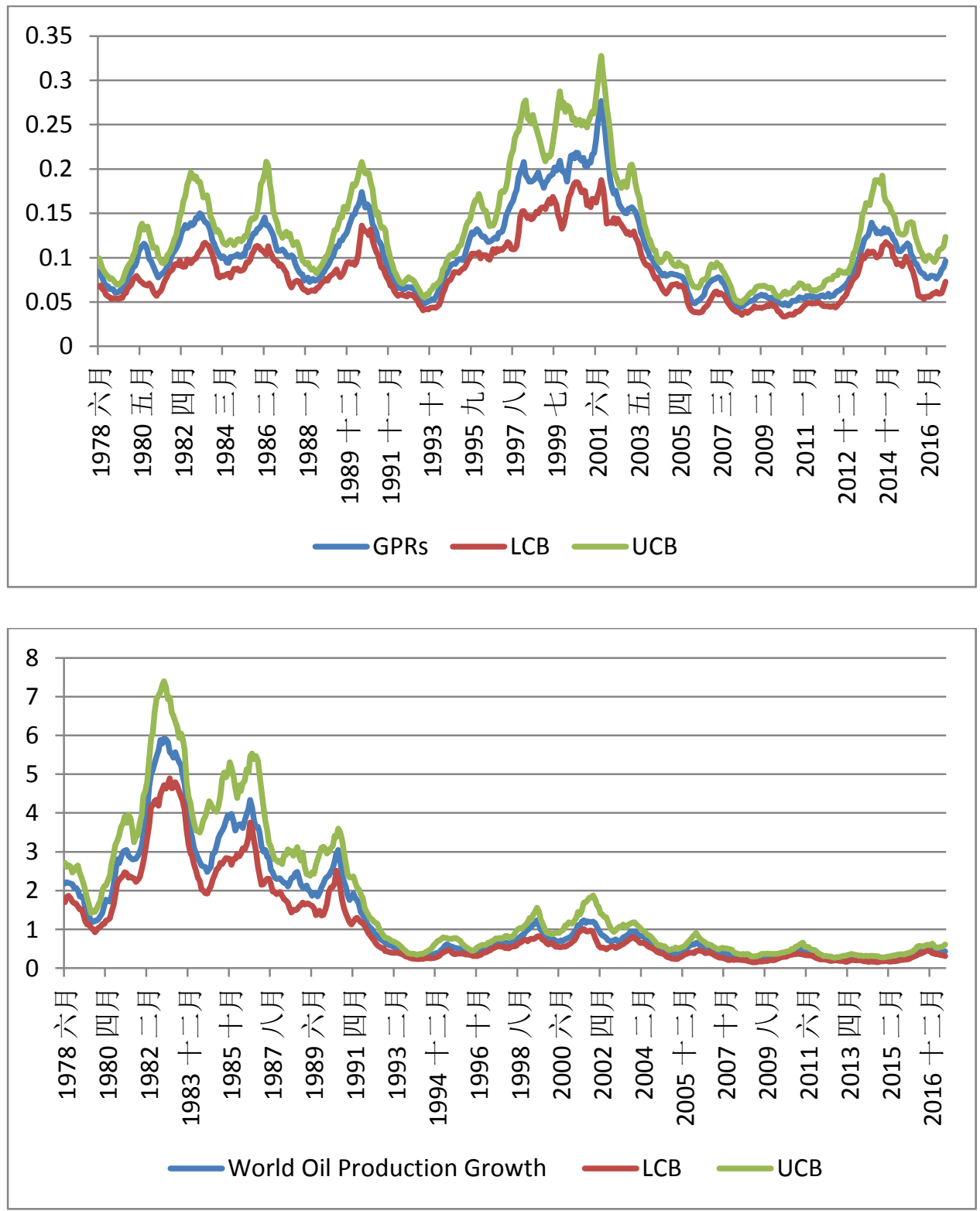

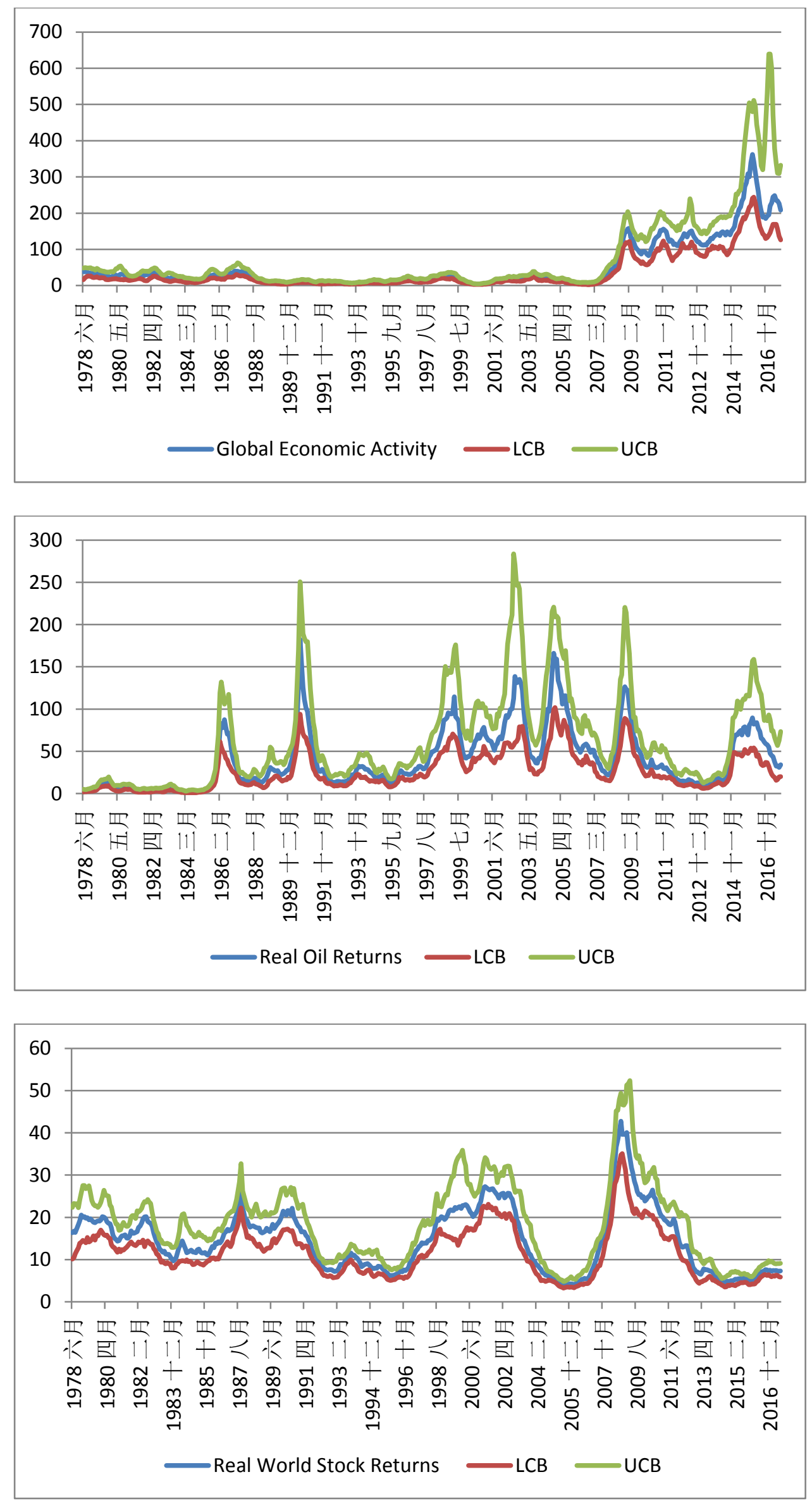

Note: LCB and UCB in Figures stand for lower and upper $68 \%$ confidence bands. 
Figure 3. Dynamic Correlations from the TVP-SVAR Model

3(a). Dynamic Correlation between GPRs and Real Oil Returns

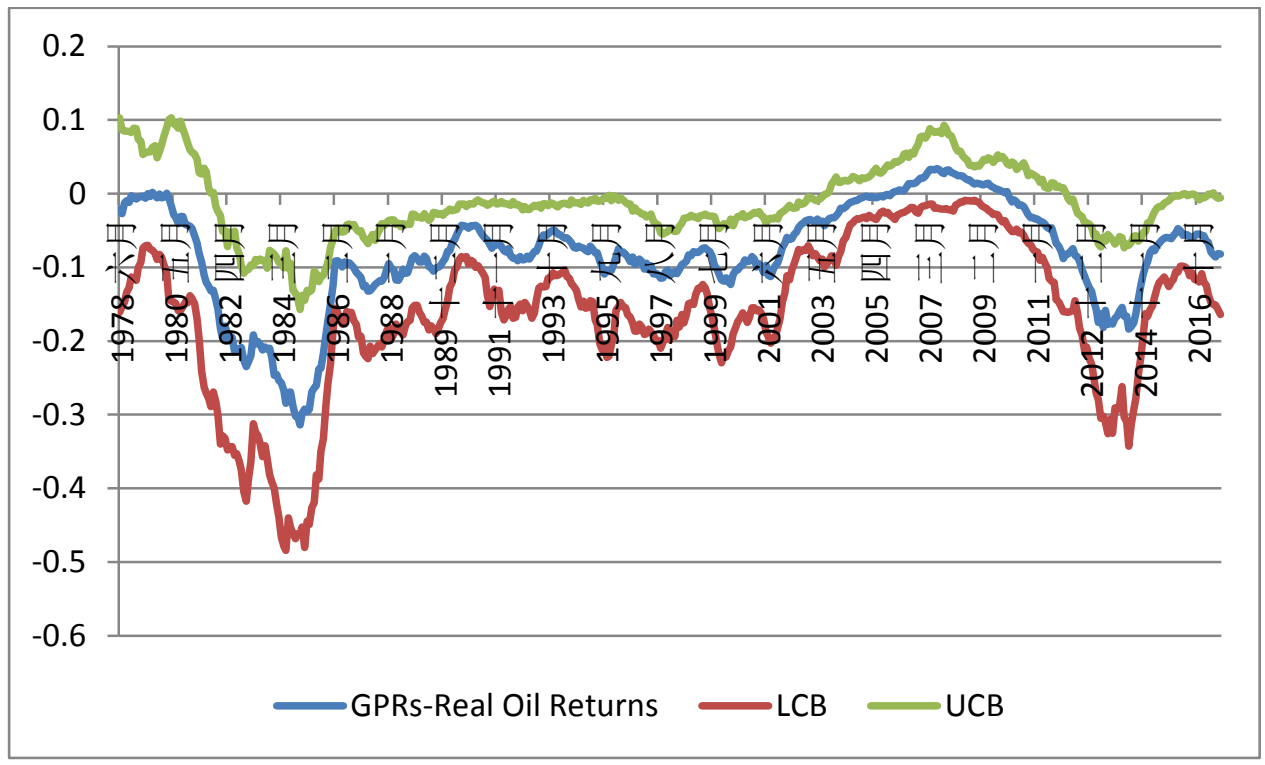

3(b). Dynamic Correlation between GPRs with Growth in World Production of Oil, Global Economic Activity, and Real Stock Returns

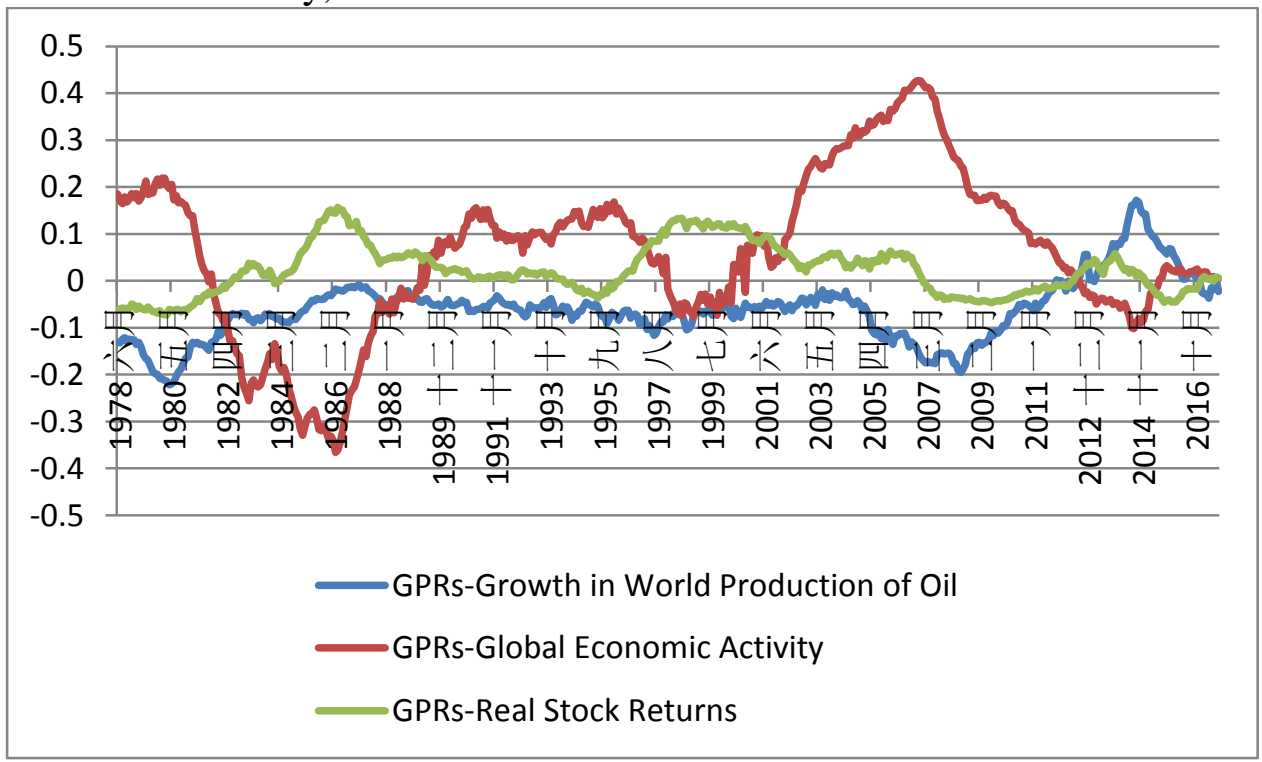

Note: LCB and UCB in Figure 3(a) stands for lower and upper 68\% confidence bands. 


\section{APPENDIX:}

Figure A1. Data Plot:

GPR

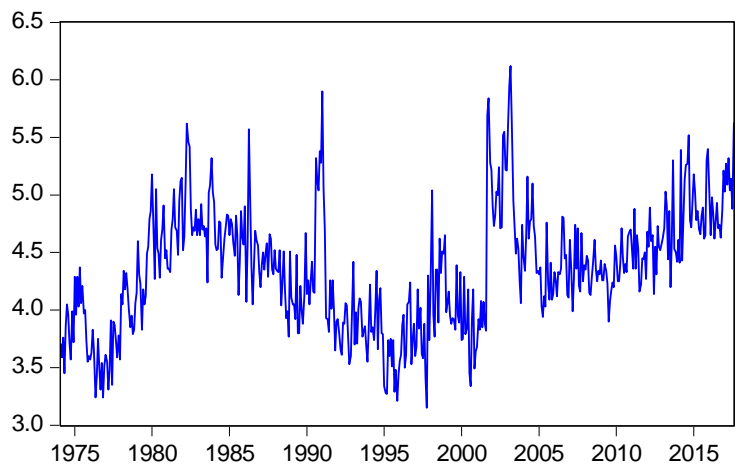

GLOBAL ECONOMIC ACTIVITY

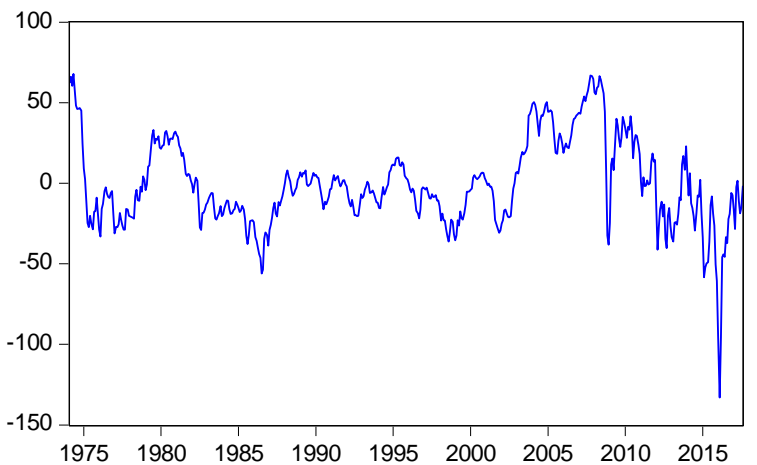

REAL STOCK RETURNS

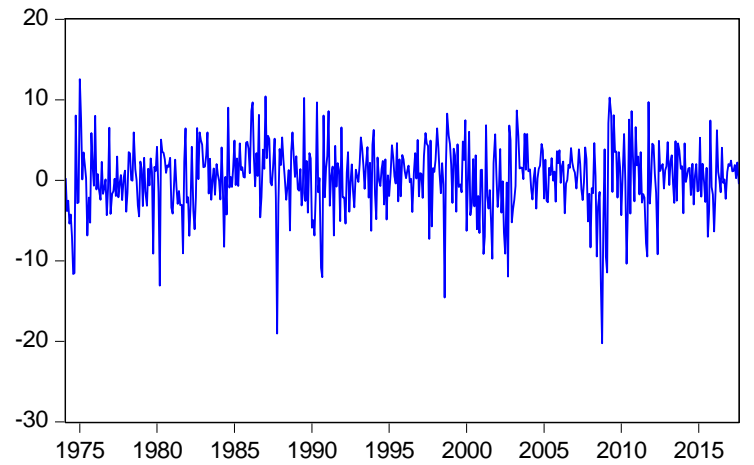

WORLD OIL PRODUCTION GROWTH

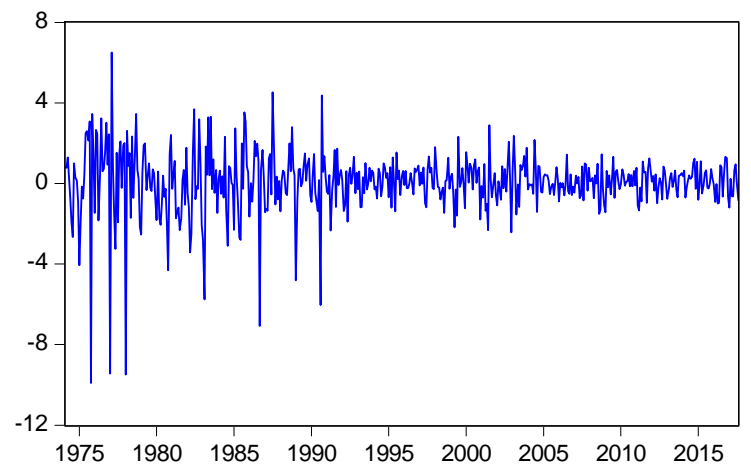

REAL OIL RETURNS

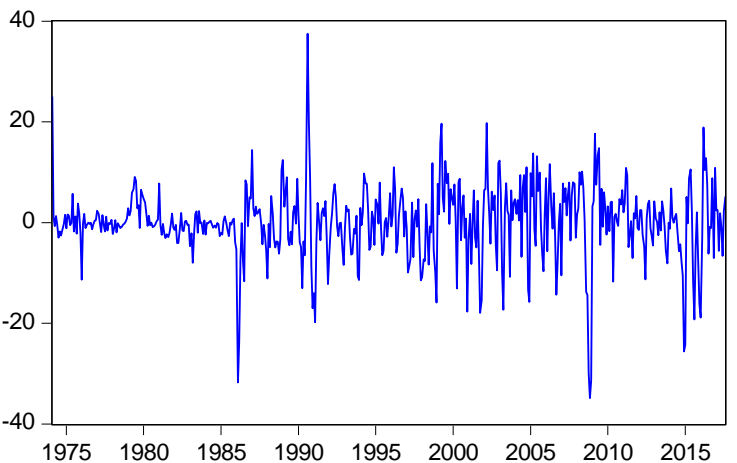


Figure A2. Dynamic Correlations between Real Oil Returns, Geopolitical Attacks (GPAs), Geopolitical Risks (GPRs), and Geopolitical Threats (GPTs)

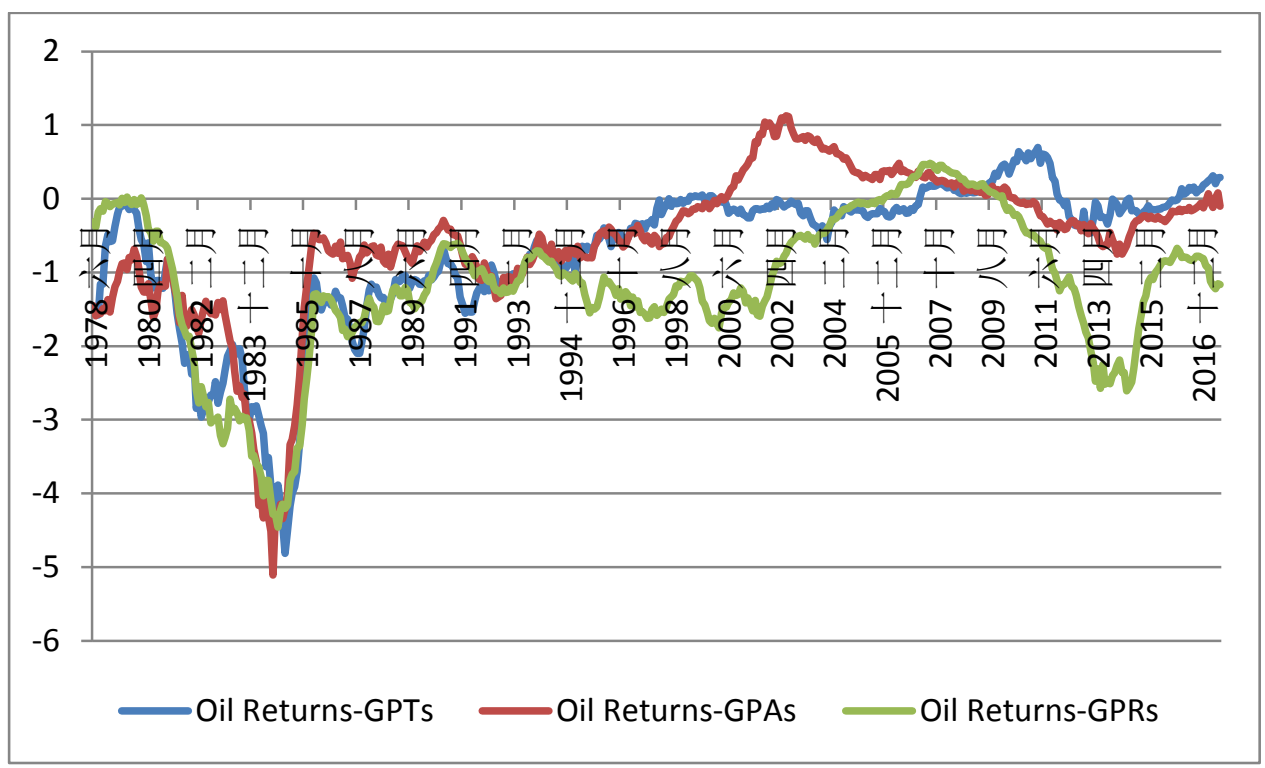

Table A1. Summary Statistics

\begin{tabular}{|c|c|c|c|c|c|}
\cline { 2 - 6 } \multicolumn{1}{c|}{} & \multicolumn{5}{c|}{ Variable } \\
\hline Statistic & GPRs & $\begin{array}{c}\text { World Oil Production } \\
\text { Growth }\end{array}$ & $\begin{array}{c}\text { Global Economic } \\
\text { Activity }\end{array}$ & $\begin{array}{c}\text { Real Oil } \\
\text { returns }\end{array}$ & $\begin{array}{c}\text { Real Stock } \\
\text { Returns }\end{array}$ \\
\hline Mean & 4.3472 & 0.0713 & -0.6999 & -0.0102 & 0.2359 \\
\hline Median & 4.3300 & 0.1727 & -4.2700 & -0.0247 & 0.5975 \\
\hline Maximum & 6.1200 & 6.4986 & 67.8000 & 37.4653 & 12.5678 \\
\hline Minimum & 3.1500 & -9.9073 & -133.0000 & -34.8701 & -20.2643 \\
\hline Std. Dev. & 0.5242 & 1.5301 & 26.6518 & 7.2958 & 4.3198 \\
\hline Skewness & 0.2981 & -1.6618 & 0.1632 & -0.5724 & -0.7041 \\
\hline Kurtosis & 2.9792 & 13.5676 & 4.2614 & 7.3525 & 4.9658 \\
\hline Jarque-Bera & 7.7552 & 2674.2570 & 36.9957 & 441.3780 & 127.4229 \\
\hline Probability & 0.0207 & 0.0000 & 0.0000 & 0.0000 & 0.0000 \\
\hline Observations & \multicolumn{5}{|c|}{523} \\
\hline
\end{tabular}

Note: Std. Dev. stands for standard deviation, while probability is the $p$-value for the Jarque-Bera test, with the null hypothesis of normality. 